\title{
Discontinuation of Reversible Long-Acting Contraceptive and Associated Factors among Female Users in Health Facilities of Hawassa City, Southern Ethiopia: Cross-Sectional Study
}

This article was published in the following Dove Press journal:

Open Access Journal of Contraception

\author{
Belay Amare Abebe' \\ Nega Assefa ${ }^{2}{ }^{2}$ \\ Bezatu Mengistie (D) ${ }^{2}$ \\ 'Department of Midwifery, College \\ Medicine and Health Sciences, University \\ of Hawassa, Hawassa, Ethiopia; ${ }^{2}$ School of \\ Public Health, College of Health and \\ Medical Sciences, University of Haramaya, \\ Harar, Ethiopia
}

Background: Despite improvement in the availability and use of reversible long-acting contraception, discontinuation is becoming a public health concern. A significant proportion of women discontinuing the service before its due date, which is of concern in the health system with regard to its consequences, may lead to a program failure. In addition, there is a paucity of information on discontinuation of reversible long-acting contraceptives and associated factors in the study area. Therefore, this study aimed to assess discontinuation of reversible long-acting contraceptives and associated factors among female users in health facilities of Hawassa city, southern Ethiopia, 2019.

Methods: Institution-based cross-sectional design was used. Systematic sampling was used to select study participants. Women who were users of long-acting contraceptives and had come to selected health facilities for method-related reasons were included in the study. Data collectors approached and recruited participants before they contacted their care providers. Data were collected from study subjects using a pretested, structured questionnaire through face-to-face interviews after participants had contacted care providers. Results are presented using the crude and adjusted ORs with corresponding 95\% CIs.

Results: The overall proportion of reversible long-acting contraceptive discontinuation was $56.6 \%$ (95\% CI 52.30\%, 61.10\%). Maternal education at primary level (AOR 2.33, 95\% CI 1.15-4.74), lack of counseling (AOR 2.50, 95\% CI 1.01-6.18), side effects (AOR 2.10, 95\% CI 1.31-3.34), and desire to be pregnant (AOR 2.22; 95CI 1.50-3.30) were the major factors in discontinuation.

Conclusion: In this study, the overall proportion of discontinuation of reversible long-acting contraceptives was high. Maternal education at primary level, lack of counseling, side effects, and desire to be pregnant were the key factors associated with discontinuation of the contraceptives. Health professionals should provide counseling on the side effects before insertion.

Keywords: factors, discontinuation, reversible long-acting contraceptives

\section{Background}

Family planning is a process that usually involves a discussion between a woman, a man, and a trained family-planning service provider focusing on family health and a couple's desire either to limit or space their family size. ${ }^{1}$ Contraceptive discontinuation is the removal of such methods by women for any reason. ${ }^{2}$ Long-acting reversible contraception (LARC) comprises methods of birth control that provide effective
Correspondence: Belay Amare Abebe PO Box 1560

Tel +25I-9I-0I4-2I 97

Email gideteb60@gmail.com
Open Access Journal of Contraception 2020: I I I|3-123 in $\mathbf{D}$ 
contraception for longer periods without requiring user action, and includes intrauterine devices (IUDs) and implants. ${ }^{2,3}$ IUDs were first used at the beginning of the 20th century. ${ }^{2,3}$ The implants are also long-acting and extremely effective at preventing pregnancy, with a clinical failure rate $<1 \%{ }^{19}$

Discontinuation of effective methods of contraception is a universal problem, although rates vary widely by population and country. ${ }^{8}$ Globally, an estimated 33 million accidental pregnancies are reported to occur among women using either traditional or modern contraceptive methods. ${ }^{8,24}$ From evidence of 60 demographic and health surveys conducted on causes and consequences of contraceptive discontinuation, an average of $38 \%$ of women discontinued the use of reversible by the 12 th month and $64 \%$ by the 36 th month in the 19 countries covered. Twelve-month discontinuation for IUDs was $13 \%{ }^{24}$

According to a report based on developing countries, $13.1 \%$ of IUD users discontinued use during the first 12 months, $26.3 \%$ within 24 months, and $36.7 \%$ within 3 years of use. ${ }^{2,3}$ Discontinuation of IUDs within the first 12 months ranges from $13 \%$ to $47 \%$, and discontinuation of Implanon within the first year ranges from $2 \%$ in Nigeria to $23 \%$ in the UK. ${ }^{2,3}$ Contraceptive discontinuation contributes to unplanned pregnancy, unwanted births, and termination of pregnancy, which poses a risk to women's health. ${ }^{7,21}$ Every year, about a third of the world's 182 million pregnancies are unplanned. ${ }^{7,21}$ Unplanned pregnancy results in larger families and ultimately contributes to higher overall fertility rates, which may result in social, economic, and physical health disabilities. $^{18,23}$

Only $8 \%$ of married women in Ethiopia use implants and 2\% IUDs. ${ }^{12,25}$ Apart from low utilization, premature removal is common for unknown reasons. In addition, there is a paucity of information on discontinuation and factors associated with LARC use in the study area and in the country at large. Therefore, this study aimed to assess discontinuation of LARC and associated factors among LARC users in health facilities of Hawassa city, southern Ethiopia, from March 1 to April 1, 2019.

The findings of this study will enhance the planning and decision-making capacity of health professionals to seek possible solutions to community problems in collaboration with the stakeholders concerned. In addition, the findings will help local program managers, planners, and other concerned organizations working in the field of family planning and maternal health to plan new strategies and prepare training programs based on the identified factors to enhance retention of utilization in the community. Finally, this study will provide baseline data for other researchers to undertake future study in the field.

Conceptual framework (Figure 1)

\section{Methods}

This was an institution-based cross-sectional study. The study setting was Hawassa, capital of the Southern Nations, Nationalities, and Peoples' Region, and Sidama Zone, located $275 \mathrm{~km}$ south of the capital of Ethiopia Addis Ababa. Hawassa's city administration is subdivided into eight subcities, of which seven are urban with 21 kebeles and one periurban with 12 kebeles, with a total population of 387,087 in $2017 .^{11}$ The study was conducted at nine health facilities: Hawassa University Referral Hospital (HURH), Adare General Hospital, the Hawassa Family Guidance Association, Marie Stopes International clinic, Millennium health center $(\mathrm{HC})$, Alamura $\mathrm{HC}$, Adare HC, Tulla HC, and Tilite HC of Hawassa, southern Ethiopia, from March 1 to April 1, 2019.

\section{Participants}

The source population was all reproductive-age women (15-49 years) who were current users of LARC in all health institutions of Hawassa. The study population comprised all reproductive-age women who were current users of LARC and had come to the selected health institutions for reasons related to contraceptive methods during the actual data-collection period.

\section{Variables}

The dependent variable was discontinuation of LARC (yes/ no), and independent variables were sociodemographic characteristics (age, marital status, religion, occupation, and education), obstetric factors (number of children, parity, and abortion), and method-related factors (side effects, past contraceptive utilization, desire for pregnancy, follow-up, and counseling).

\section{Eligibility Criteria, Sample Size, and Objectives}

The inclusion criterion was current users of LARC who had come to the selected institutions for any reason related to LARC during the data-collection period. The exclusion criterion was inability to communicate and respond, eg, due to hearing loss. To determine the sample size for this study, the outcome variable and various factors significantly associated with the outcome variable were 


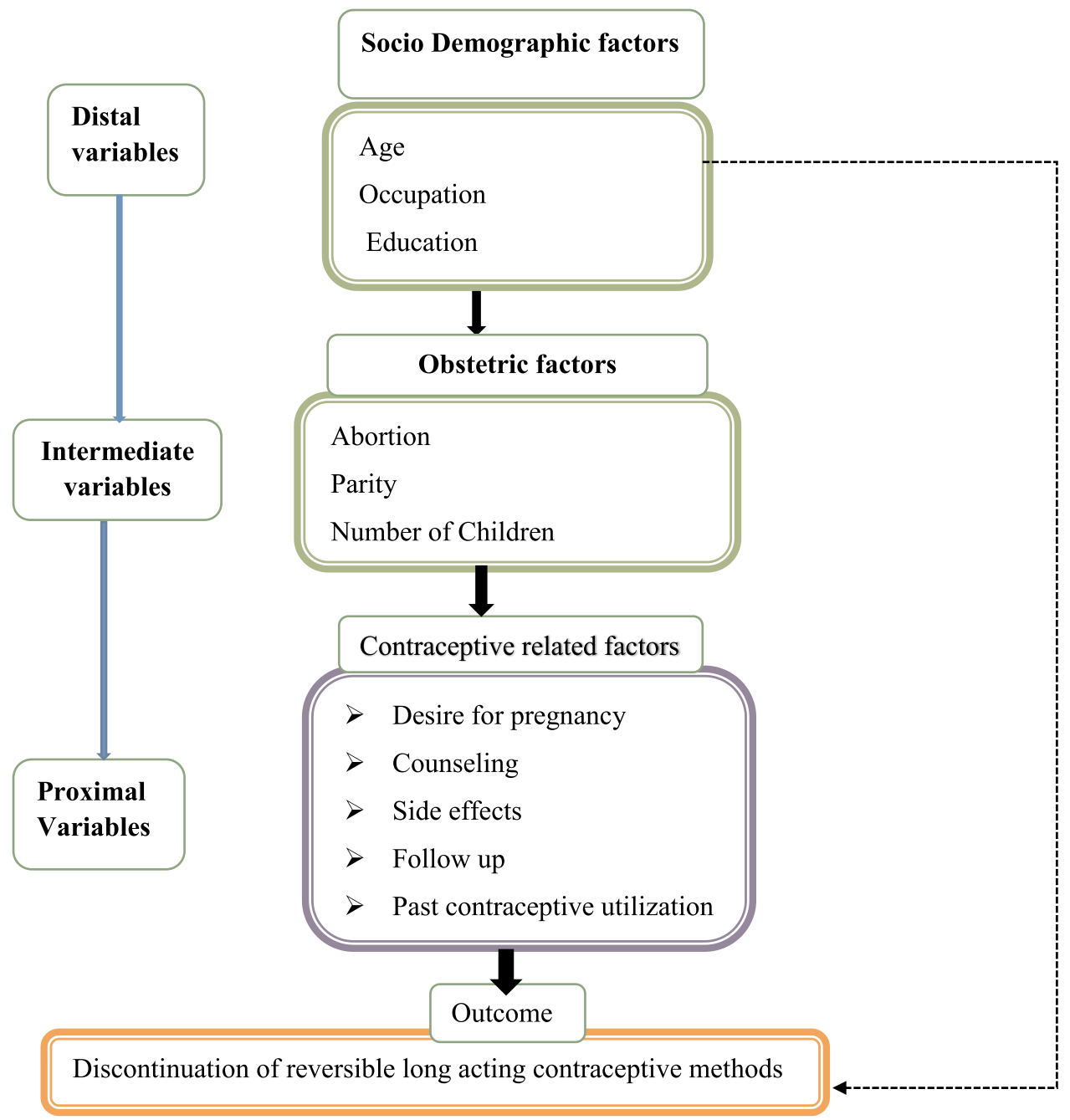

Figure I Conceptual framework for the study developed by the principal investigator.

considered. Accordingly, for the first and second specific objectives, the sample size was calculated separately and the larger one adopted for use in this study.

Specific objective 1 concerned the magnitude of discontinuation of LARC. The sample size was calculated by using a single population-proportion formula:

$$
n=\frac{\left(z_{\alpha / 2}\right)^{2} \times p(1-p)}{d^{2}}
$$

where $n$ is the minimum sample size required, $p$ the expected proportion of discontinued mothers, $z=1.96$ ( $95 \% \mathrm{CI}$ ) and $d=0.05$ the margin of error between the sample and the population. For this study $p=50 \%$, because there was no published study in line with this title. Applying the formula by substituting these values into the equation gives 384 . With the addition of a $10 \%$ nonresponse rate, the final sample size became 422 for the first specific objective. Specific objective 2 concerned factors associated with discontinuation of LARC. The sample size of the second specific objective of this study was determined by considering factors that were significantly associated with the outcome variable, with a two-sided confidence level of $95 \%$, margin of error $5 \%$, power $80 \%$, and ratio of exposed to unexposed 1:1 using Epi Info version 7 .

\section{Sampling Technique/Procedure}

Both hospitals (ie, HURH and Adare General Hospital), five HCs, (ie Millennium, Adare, Tilite, Tulla, and Alamura) and two NGO clinics (ie, Hawassa Family Guidance Association and Hawassa Marie Stopes International) were randomly selected for this study. In order to ensure a proportionate allocation of the total sample size determined, average 6-month client flows of 
each selected health institution were considered prior to the start of data collection. The information obtained from the 6-months enrollment record (June-December 2018) from the family-planning registry books showed that a total of 4,510 women had used LARCs within 6 months in the selected institutions.

As the result, the average 6-month client flow obtained from registration books of $\mathrm{HURH}$, Adare General Hospital, Hawassa Family Guidance Association, Marie Stopes International, Millinium HC, Alamura HC, Adare HC, Tulla HC, and Tilite HC was 600, 660, 640, 600, 410, 480, 400, 460, and 250 respectively. The sample was allocated proportionally to each selected institution. Data collectors approached and recruited LARC users who had come to the selected clinics for contraceptive- related reasons. The total sample-size requirement was met by the systematic sampling of daily case load (ie, $k$ th value for all ranges: 1.66-1.72). Every second woman was included in the sample until the total sample size for this study had been obtained in all selected health facilities (Figure 2). LARC discontinuation was regarded as cumulative probability of stopping use of contraception by a specific duration, while early Implanon discontinuation referred to removal of Implanon by health professionals before 2.5 years of utilization.

\section{Data Processing and Analysis}

Data entry was done using Epi Data version 3.1 and then exported to SPSS version 22 for analysis. Bivariate analysis was performed to reveal the association of each variable with LARC discontinuation at $p<0.25$. Multicollinearity tests were carried out to checklinear correlations among independent variables. The HosmerLemeshow goodness-of-fit test was used to check model fitness. Based on the findings of bivariate analysis, variables with $p<0.25$ were entered into multivariate logistic regression analysis with a 95\% confidence level and 5\% significance level. In multivariate logistic regression analysis, variables at AOR with 95\% CI and $p<0.05$ were considered as statistically significant.

\section{Results}

\section{Sociodemographic Characteristics}

A total of 442 women responded to the questionnaire, for a response rate of $100 \%$. The age of the study participants was 19-45 years, with mean $27.2 \pm 4.6$ years. Table 2 shows that $201(45.5 \%)$ of the total respondents were aged 25-29. The majority of participants, 431 (97.5\%), were married, and about 267 (60.4\%) were Protestant Christians, followed by Orthodox Christians - 131 (29. $6 \%$, Table 2).

\section{Obstetric-Related Characteristics}

Obstetric history was one of the factors evaluated in the study. In sum, 236 (53.4\%) respondents had given birth one to two times $177(40.0 \%)$ more than three times. Of those who had given birth, 263 (59.5\%) had one to two children alive and $130(29.4 \%)$ three to four children alive. Among the participants, 142 (32.1\%) women had a history of abortion and 283 (64\%) desired another pregnancy. Of those who desired another pregnancy, 106 (37.5\%) and $177(62.5 \%)$ women desired to become pregnant within 2 and after 2 years, respectively (Table 3 ).

\section{Contraceptive-Related Characteristics}

Of all participants, 263 (59.5\%), 91 (20.6\%), and 88 $(19.9 \%)$ were Implanon, IUCD, and Jadelle users, respectively. A total of $301(68.1 \%)$ had used contraceptives before the LARC they were using during the study period. Of these, $233(77.4 \%)$ had used injectables followed by oral contraceptive pills 118 (39.2\%). Of all participants, 379 (85.31\%) got the LARC insertion from government institutions, while 310 (70.1\%) had chosen the contraceptives on their own. This might have been as a result of good awareness among participants of LARC and/or pressure from health providers to use it. From reasons for

Table I Sample-Size Determination for Magnitude and Associated Factors of LARC Discontinuation

\begin{tabular}{|l|l|l|l|l|}
\hline & Exposed Outcome, \% & Unexposed Outcome, \% & Sample Size & Reference \\
\hline Counseling & 20 (counseled) & 9.6 (not counseled) & 402 & {$[6]$} \\
Removal due to side effects & 75.6 (side effect faced) & 60.2 (side effect not faced) & 312 & 166 \\
Follow-up & 35.9 (had follow-up) & 15.76 (had no follow-up) & $166]$ & {$[22]$} \\
\hline
\end{tabular}

Notes: Calculated sample size of the second objective was larger than that of the first objective. By adding a $10 \%$ nonresponse rate, $n=402 \times 0.1+402=442$, the final sample size. 
Six months' enrollment in Heath institutions of Hawassa city administration in both public hospitals, five HCs and two NGO clinics from family planning registration book, for sample selection (June-December/2018).
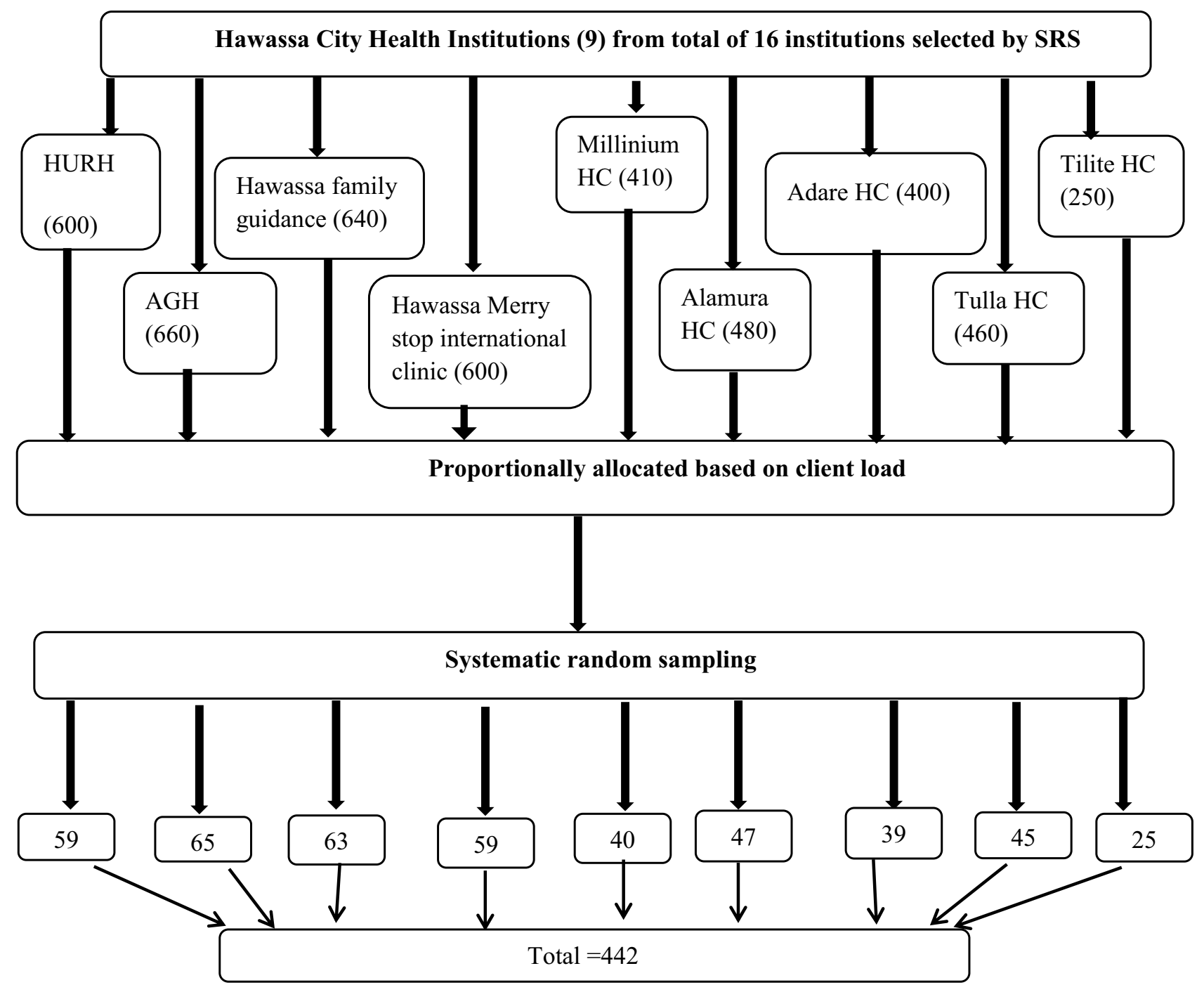

Figure 2 Schematic presentation of sampling procedure for the study developed by the principal investigator.

choosing methods, $192(43.4 \%)$ and $107(24.2 \%)$ were long protection and removability at any time, respectively.

A total of $411(93.0 \%)$ and $319(72.2 \%)$ participants received counseling on the benefits and side effects of LARC during insertion, respectively, 419 (94.8\%)participants had an appointment for follow-up during LARC use, while 39 (31.4\%) had experienced side effects during LARC use. Suggested reasons for discontinuation showed that side effects were the major driver, accounting for 92 (36.8\%), followed by $72(28.8 \%)$ planning to conceive in the near future (Table 4). Among participants who discontinued LARC due to non-side effect reasons, desire for another pregnancy accounted for 72 (28.8\%), followed by
67 (26.8\%) seeking a switch of method after service end. Others were husband going abroad, husband's objection, divorce, and health concerns (19, 7.6\%). Among women who discontinued LARC due to side effects, menstrual disruption accounted for 65 (69.1\%), followed by 22 (23.7\%) for weight gain (Figure 3).

\section{Magnitude of Reversible Long-Acting Contraceptive Discontinuation}

The study aimed to assess the proportion of LARC discontinuation among women who were LARC users and had come with method-related complaints to health 
Table 2 Sociodemographic Characteristics of Study Participants $(n=442)$

\begin{tabular}{|c|c|c|}
\hline & Frequency & Percentage \\
\hline \multicolumn{3}{|l|}{ Age, years } \\
\hline $19-24$ & 112 & 25.3 \\
\hline $25-29$ & 201 & 45.5 \\
\hline $30-34$ & 93 & 21.0 \\
\hline$\leq 35$ & 36 & 8.2 \\
\hline \multicolumn{3}{|l|}{ Marital status } \\
\hline Single & 11 & 2.5 \\
\hline Married & 431 & 97.5 \\
\hline \multicolumn{3}{|l|}{ Religion } \\
\hline Orthodox & $|3|$ & 29.6 \\
\hline Muslim & 32 & 7.2 \\
\hline Protestant & 267 & 60.4 \\
\hline Catholic & 10 & 2.3 \\
\hline Other* & 2 & 0.5 \\
\hline \multicolumn{3}{|l|}{ Ethnicity } \\
\hline Sidama & 175 & 39.6 \\
\hline Wolayta & 101 & 22.9 \\
\hline Amhara & 84 & 19.0 \\
\hline Gurage & 34 & 7.7 \\
\hline Oromo & 20 & 4.5 \\
\hline Other* & 28 & 6.3 \\
\hline \multicolumn{3}{|l|}{ Occupation } \\
\hline Housewife & 196 & 44.3 \\
\hline Merchant & 79 & 17.9 \\
\hline Private employee & 54 & 12.2 \\
\hline Government employee & 84 & 19.0 \\
\hline Student & 29 & 6.6 \\
\hline \multicolumn{3}{|l|}{ Maternal education } \\
\hline Unable to read or write & 68 & 15.4 \\
\hline Able to read and write & 51 & 11.5 \\
\hline Primary & 112 & 25.3 \\
\hline Secondary & 101 & 22.9 \\
\hline College and above & 110 & 24.9 \\
\hline \multicolumn{3}{|l|}{ Paternal education $(n=43 I)$} \\
\hline Unable to read or write & 33 & 7.7 \\
\hline Able to read and write & 30 & 7.0 \\
\hline Primary & 69 & 16 \\
\hline Secondary & 126 & 29.2 \\
\hline College and above & 173 & 40.1 \\
\hline \multicolumn{3}{|l|}{ Husband's occupation ( $n=431)$} \\
\hline Farmer & 27 & 6.3 \\
\hline Merchant & 166 & 38.5 \\
\hline Private employee & 69 & 16.0 \\
\hline Government employee & 151 & 35.0 \\
\hline Student & 7 & 1.6 \\
\hline Other & 11 & 2.6 \\
\hline
\end{tabular}

facilities during the study period. From 442 study participants, 56.6\% (95\% CI 52.3\%-61.1\%) had overall LARC discontinuation (Figure 4). Mean duration of LARC utilization was $2.3 \pm 1.3$ years.

\section{Factors Associated with Reversible Long- Acting Contraceptive Discontinuation}

Findings from bivariate analysis revealed that age, maternal education, paternal education, past contraceptive utilization, desire to be pregnant in the near future, lack of counseling on possible benefits of contraceptives, appointments for followup, and developing side effects were significantly associated with LARC discontinuation $(p<0.25)$. On multivariate logistic regression analysis only, maternal education, side effects, lack of counseling on possible benefits, and desire to be pregnant in the near future were found statistically significant in LARC discontinuation (Table 5).

\section{Discussion}

The proportion of LARC discontinuation among LARCs user women was high. Factors such as maternal education at primary level, lack of counseling on possible benefits of LARCs, side effects, and desire to be pregnant in the near future were significantly associated with discontinuation of LARC. The proportion of LARC discontinuation among women who were users of LARCs was $56.6 \%$. This finding is in line with a study conducted in Australia - 60\%. ${ }^{13}$ However, the current proportion is lower than a study conducted in Debre Tabor $65 \%{ }^{16}$ This variation might be due to study nature or study participants. In the Debre Tabor study, participants were both urban and rural residents, but urban only in this study. Awareness of the effects of contraceptives might be higher among urban residents. Moreover, it might have been due to efforts made to improve counseling, especially for those mothers with menstrual disruption and weight-gain problems. These factors might have an impact on lower proportions of LARC discontinuation.

The current proportion was also higher than studies conducted in the US (25.2\%), Netherland (47\%), Jordan (45\%), Pakistan (18\%), Egypt (36\%), Yemen (43\%), Cambodia (45\%), Ilorin, Nigeria (26.5\%), Abakaliki, southeast Nigeria (29.6\%), and Ofla Tigray (16\%). ${ }^{4,6,10,14,21,23}$ This difference might be due to lack of preinsertion counseling, particularly about the possible benefits and side effects of methods, compared to other studies. In addition, it might be due to the educational status of the study participants, because more 
Table 3 Obstetric-Related Factors for Discontinuation of Reversible Long-Acting Contraceptives $(n=442)$

\begin{tabular}{|c|l|l|}
\hline & Frequency & Percentage \\
\hline Parity & & \\
0 & 29 & 6.6 \\
$\mathrm{I}-2$ & 236 & 53.4 \\
$3+$ & 177 & 40.0 \\
\hline Number of living children & & \\
0 & 31 & 7.0 \\
I-2 & 263 & 59.5 \\
$3-4$ & 130 & 29.4 \\
$5+$ & 18 & 4.1 \\
\hline History of abortion & & \\
Yes & 142 & 32.1 \\
No & 300 & 67.9 \\
\hline Desire for pregnancy & & \\
Yes & 283 & 64.0 \\
No & 159 & 36.0 \\
\hline When they wanted to become & & \\
pregnant (n=283) & & \\
Within 2 years & 106 & 37.5 \\
After 2 years & 177 & 62.5 \\
\hline
\end{tabular}

than half the current participants were had only primary level and below. ${ }^{4,10,21,23}$ Other reasons for differences in the current proportion might be the higher sample size of the current study compared to other studies, ${ }^{6,10,14}$ or sociocultural differences of respondents across the study areas. Lastly, the difference might be because the current study incorporated all LARC methods.

In the present study, the likelihood of discontinuing LARC among women who developed side effects like menstrual irregularity and weight gain were 2.1 times higher than those who did not face side effects. This is consistent with studies conducted in Abakaliki, southeast Nigeria, Debre Tabor, Arsi, Oromia, Jos, Nigeria, and Tigray. ${ }^{6,9,14,16,17}$ Possible reason might be exposure to side effects contributing to discontinuation. In addition to this, respondents who had discontinued LARC due to side effects might have been intolerant of the side effects and feared happening different complications with their health in the future. Lastly, it might be due to similarity of study design and respondents, as well community awareness of LARC.

This study revealed that women who did not get preinsertion counseling service about possible benefits of LARC were 2.5 times more likely to discontinue than those who got counseling services about possible benefits. This is consistent with studies in Tigray, Debre Tabor, India, Diguna Fango, and
Table 4 Contraceptive-Related Characteristics for Discontinuation of Reversible Long-Acting Contraceptives $(n=442)$

\begin{tabular}{|c|c|c|}
\hline & Frequency & Percentage \\
\hline \multicolumn{3}{|l|}{ Type of LARC used } \\
\hline Implant & 263 & 59.5 \\
\hline IUCD & 91 & 20.6 \\
\hline Jadelle & 88 & 19.9 \\
\hline \multicolumn{3}{|l|}{ Contraceptive use before LARCs } \\
\hline Yes & 301 & 68.1 \\
\hline No & $|4|$ & 31.9 \\
\hline \multicolumn{3}{|l|}{$\begin{array}{l}\text { Type of contraceptive used } \\
\text { before LARCs }\end{array}$} \\
\hline OCP & 118 & 39.2 \\
\hline Injectable & 233 & 77.4 \\
\hline IUCD & 12 & 21.6 \\
\hline Implant & 66 & 4.0 \\
\hline \multicolumn{3}{|l|}{ Place of insertion } \\
\hline Hospital & 211 & 47.7 \\
\hline Health center & 166 & 37.6 \\
\hline Health post & 2 & 0.5 \\
\hline Family & 57 & 12.9 \\
\hline Other* & 6 & 1.4 \\
\hline \multicolumn{3}{|l|}{ Counseling on benefits of LARCs } \\
\hline Yes & 411 & 93.0 \\
\hline No & 31 & 7.0 \\
\hline \multicolumn{3}{|l|}{$\begin{array}{l}\text { Counseling on side effects of } \\
\text { LARCs }\end{array}$} \\
\hline Yes & 319 & 72.2 \\
\hline No & 123 & 27.8 \\
\hline \multicolumn{3}{|l|}{$\begin{array}{l}\text { Estimation of information } \\
\text { participants got during } \\
\text { counseling (satisfaction) }\end{array}$} \\
\hline Yes & 341 & 77.1 \\
\hline No & 101 & 22.9 \\
\hline \multicolumn{3}{|l|}{$\begin{array}{l}\text { Have you ever experienced side } \\
\text { effects? }\end{array}$} \\
\hline Yes & 139 & 31.4 \\
\hline No & 303 & 68.6 \\
\hline \multicolumn{3}{|l|}{ Who chose LARCs? } \\
\hline Own choice & 310 & 70.1 \\
\hline My husband & 35 & 7.9 \\
\hline Health professional & 94 & 21.3 \\
\hline Health extension & 2 & 0.5 \\
\hline My neighbor & 1 & 0.2 \\
\hline \multicolumn{3}{|l|}{ Reason for choosing this method } \\
\hline Safety & 89 & 20.1 \\
\hline Long protection & 192 & 43.4 \\
\hline Can be removed at any time & 107 & 24.2 \\
\hline
\end{tabular}

(Continued) 
Table 4 (Continued).

\begin{tabular}{|l|l|l|}
\hline & Frequency & Percentage \\
\hline Immediate fertility return & 54 & 12.2 \\
\hline $\begin{array}{l}\text { Follow-up } \\
\text { Yes }\end{array}$ & 419 & 94.8 \\
No & 23 & 5.2 \\
\hline $\begin{array}{l}\text { Removal due to side effects } \\
(\mathbf{n}=\mathbf{2 5 0}) \\
\text { Yes }\end{array}$ & & \\
No & 92 & 36.8 \\
\hline
\end{tabular}

Note: *Marie Stopes International clinic, private hospitals, and other clinics.

the Philippines. ${ }^{5,6,16,19,22}$ Providing preinsertion or duringinsertion counseling about benefits and side effects of LARC was positively associated with use of the methods. ${ }^{19,22}$ As such, a possible justification reason for this factor might be lack of preplacement counseling and support by service providers to help women continue on contraception. In addition, sociocultural differences, lack of skilled counselors, outlook and level of understanding of participants about contraceptives might be the reasons this factor being associated with discontinuation.

According to this study, the odds of discontinuation of LARC among women with primary education were 2.3 times higher than those whose with college and above. This is in line with studies conducted in Bangladesh and Diguna Fango. ${ }^{15,22}$ It might be due to similarities in educational status, level of awareness and capacity of understanding of the nature of contraceptives, and sociocultural values and norms of respondents participating in these studies.

The current study also revealed that the odds of discontinuing LARC among women who desired to be pregnant in the near future were 2.4 times higher than those who did not plan to be pregnant in the near future. This is consistent with studies conducted in Abakaliki, southeast Nigeria, Arsi, Oromia, Jos,

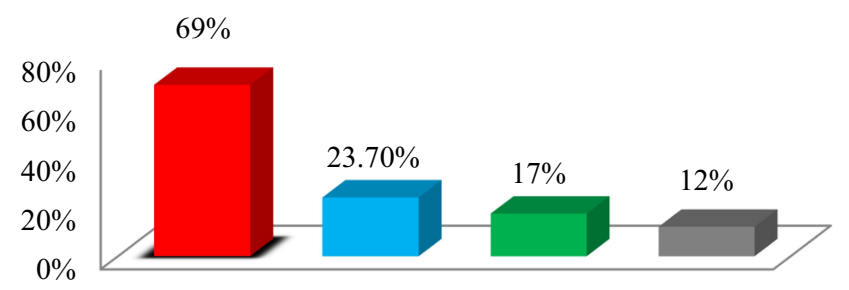

Figure 3 The main side effects for discontinuation of reversible long acting contraceptives among LARCs users wome in health facilities of Hawassa city administration, southern Ethiopia, 2019.

- menstrual irregularity; — weight gain; ;severe headache. O Others: insertion-arm pain, aching, weight reduction, and difficulty working.

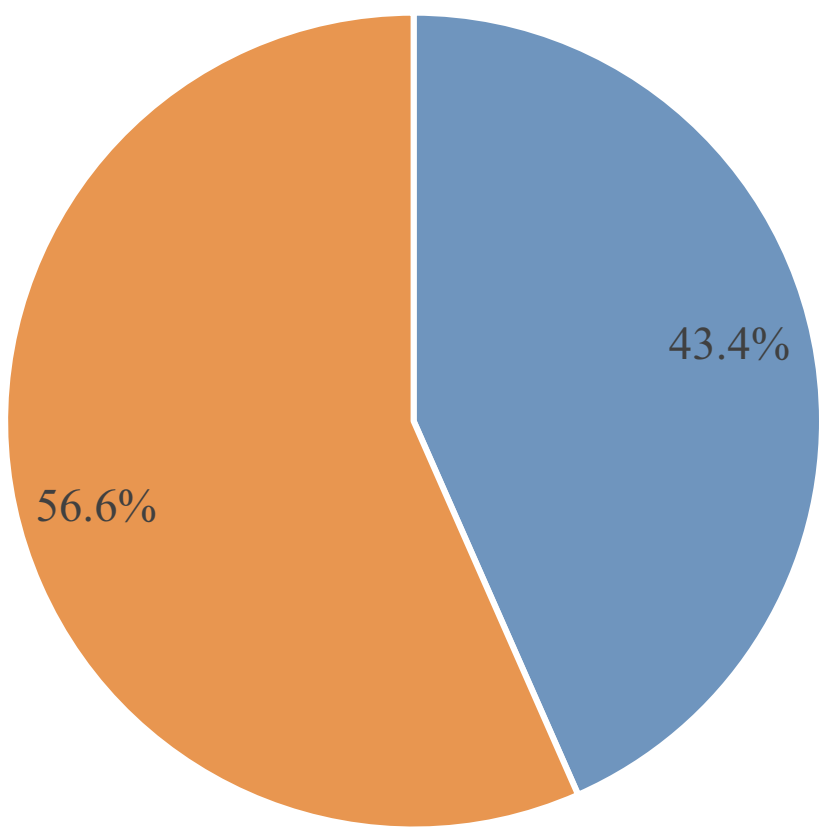

Figure 4 Proportion of reversible long-acting contraceptive methods discontinuation among female LARC users in health facilities of Hawassa city administration, southern Ethiopia, 2019.

not discontinued; 1 discontinued.

Nigeria, and Ilorin, Nigeria. ${ }^{4,9,14,17}$ This might be due to the fact that women with few or no children might intend to have children or that they might have discontinued the contraceptives. In addition to this, $70.8 \%$ of women in the present study were aged 19-29 years. Since they were young, they might intend to have more children and discontinued the contraceptives. Lastly, a majority of study participants in these studies were young, and due to a desire to have babies in the near future, they might discontinued the contraceptives.

\section{Strengths}

This study included nine health facilities (multicenter study), which increased external validity. Since it was conducted among women using LARC who had come to the selected health facilities with method-related complaints, recall bias was not challenging, unlike studies conducted on participants who had ever used LARC.

\section{Limitation}

The study was conducted in an urban health-institution setting, though the majority of the population lived rurally.

\section{Conclusion}

In this study, the overall discontinuation of LARC among women who were using LARCs was high $(56.6 \%)$. Of the overall proportion of discontinuation, reasons of side 
Table 5 Factors Associated with LARC Discontinuation $(n=442)$

\begin{tabular}{|c|c|c|c|c|c|}
\hline \multirow[b]{2}{*}{ Age, years } & \multicolumn{2}{|c|}{ LARC Discontinuation, Yes (\%)/o (\%) } & \multirow[t]{2}{*}{ COR $(95 \% \mathrm{Cl})$} & \multirow[t]{2}{*}{$P$-value } & \multirow[t]{2}{*}{ AOR (95\% Cl) } \\
\hline & & & & & \\
\hline$\leq 24$ & 37 (33.0\%) & 75 (67.0\%) & $2.838(1.313-6.134)$ & 0.008 & $2.186(0.888-5.380)$ \\
\hline $25-29$ & $83(41.3 \%)$ & I I 8 (58.7\%) & $1.990(0.969-4.088)$ & 0.061 & $1.536(0.670-3.522)$ \\
\hline $30-34$ & 51 (54.8\%) & $42(45.2 \%)$ & $\mathrm{I} .153(0.529-2.5 \mathrm{II})$ & 0.720 & $1.012(0.426-2.405)$ \\
\hline$\geq 35$ & $21(58.3 \%)$ & 15 (4I.7\%) & I & & \\
\hline \multicolumn{6}{|l|}{ Maternal education } \\
\hline Unable to read or write & $35(51.5 \%)$ & $33(48.5 \%)$ & $0.909(0.497-1.665)$ & 0.758 & $2.33 \mathrm{I}(0.9 \mid 5-5.942)$ \\
\hline Able to read and write & $24(47.1 \%)$ & $27(52.9 \%)$ & $1.085(0.558-2.109)$ & 0.810 & I.567 (0.690-3.560) \\
\hline Primary & $40(35.7 \%)$ & $72(64.3 \%)$ & $1.736(1.014-2.972)$ & 0.044 & $2.332(1.147-4.739)^{*}$ \\
\hline Secondary & $39(38.6 \%)$ & $62(61.4 \%)$ & $\mathrm{I} .533(0.886-2.65 \mathrm{I})$ & 0.126 & $1.419(0.762-2.643)$ \\
\hline College and above & $54(49.1 \%)$ & $56(50.9 \%)$ & I & & \\
\hline \multicolumn{6}{|l|}{ Paternal education } \\
\hline Unable to read or write & $17(51.5 \%)$ & $16(48.5 \%)$ & $0.755(0.358-1.591)$ & 0.460 & $0.728(0.252-2.107)$ \\
\hline Able to read and write & $16(53.3 \%)$ & 14 (46.7\%) & $0.702(0.323-1.527)$ & 0.372 & $0.517(0.200-1.332)$ \\
\hline Primary & $30(43.5 \%)$ & $39(56.5 \%)$ & I.043 (0.594-I.830) & 0.884 & $0.779(0.374-1.621)$ \\
\hline Secondary & 47 (37.3\%) & 79 (62.7\%) & I.348 (0.843-2.I56) & 0.212 & $1.099(0.619-1.949)$ \\
\hline College and above & 77 (44.5\%) & $96(55.5 \%)$ & 1 & & \\
\hline \multicolumn{6}{|l|}{ Desire for pregnancy } \\
\hline Yes & $103(36.4 \%)$ & $180(63.6 \%)$ & $2.222(I .496-3.30 I)$ & $<0.0001$ & $2.347(\mathrm{I} .496-3.68 \mathrm{I})^{* * * *}$ \\
\hline No & $89(56.0)$ & $70(44.0 \%)$ & I & & \\
\hline \multicolumn{6}{|l|}{ Contraceptive use before LARCs } \\
\hline Yes & |4| (46.8\%) & $160(53.2 \%)$ & $0.643(0.426-0.970)$ & 0.035 & $0.65 \mathrm{I}(0.4 \mathrm{I} 0-\mathrm{I} .036)$ \\
\hline No & $5 \mathrm{I}(36.2 \%)$ & $90(63.8 \%)$ & I & & \\
\hline \multicolumn{6}{|l|}{ Counseling on benefits of LARCs } \\
\hline Yes & $184(44.8 \%)$ & 227 (55.2\%) & I & & \\
\hline No & $8(25.8 \%)$ & $23(74.2 \%)$ & $2.330(1.019-5.332)$ & 0.045 & $2.496(1.008-6.18 I)^{*}$ \\
\hline \multicolumn{6}{|l|}{ Side effects } \\
\hline Yes & 49 (35.3\%) & 90 (64.7\%) & $1.642(1.084-2.485)$ & 0.019 & $2.092(1.309-3.34 \mathrm{I}) * *$ \\
\hline No & I 43 (47.2\%) & $160(52.8 \%)$ & I & & \\
\hline \multicolumn{6}{|l|}{ Follow-up } \\
\hline Yes & $185(44.2 \%)$ & $234(55.8 \%)$ & I & & \\
\hline No & 7 (30.4\%) & $16(69.6 \%)$ & I.807 (0.7284-484) & 0.202 & $1.068(0.390-2.921)$ \\
\hline
\end{tabular}

Notes: $* * * P<0.0001 ; * * P=0.002 ; * P=0.019 ; * P=0.048$.

effects and husband's objection accounted for 21.5\%. Factors like women with primary education, mothers who did not receive counseling about possible benefits of LARC, women who desired to be pregnant in the near future, and those who developed side effects were to be statistically significant in LARC discontinuation.

\section{Recommendations}

Health organizations and other concerned stakeholders could develop programs to work with health-care providers to enhance interventional measures on awareness creation and retention of LARC among the community.
Health professionals ought to give counseling on possible side effects and benefits of LARC before insertion to enhance duration of utilization. In addition to this, health providers could focus more on women whose education is primary and below during education and awareness creation on the whole characteristics of LARC. Further comprehensive study including health professionals and a community-based study are recommended.

\section{Abbreviations}

HC, health center; HURH, Hawassa University Referral Hospital; LARC, long acting reversible contraception. 


\section{Declarations}

This study was conducted in accordance with the Declaration of Helsinki.

\section{Data-Sharing Statement}

Data and materials are available.

\section{Ethical Approval and Consent to Participate}

The study was approved by the Haramaya University College of Health and Medical Sciences Institutional Health Research Ethics Review Committee (IHRERC). Permission, agreement, and consent was obtained from the Southern Nations Nationalities and Peoples Regional Health Bureau, Hawassa City Health Department, and heads of the selected health facilities prior to the study. Informed, voluntary, written, and signed consent was obtained from facility heads and participants before data collection started. Participants were also informed that their responses could not result in any harm to them, and were offer full rights and freedom to take part in the study or not. Confidentiality was maintained.

\section{Acknowledgments}

First, we would like to express our gratitude to the Haramaya University College of Health and Medical Sciences School of Nursing and Midwifery for its support, Hawassa City Health Office, all hospitals and health centers in the city, and all study participants, supervisors, and data collectors. Secondly, our appreciation extends to Haramaya University College of Health and Medical Sciences librarians and Internet center coordinators for their support and assistance in getting important materials to develop this paper.

\section{Author Contributions}

All authors made a significant contribution to the work reported, ie, in study conception, design, execution, acquisition of data, analysis, and interpretation, took part in drafting, revising, or critically reviewing the article, gave final approval to the version to be published, have agreed on the journal to which the article has been submitted, and agree to be accountable for all aspects of the work.

\section{Disclosure}

The authors report no conflicts of interest in this work.

\section{References}

1. Alemayehu M, Belachew T, Tilahun T. Factors associated with utilization of long acting and permanent contraceptive methods among married women of reproductive age in Mekelle town, Tigray region, north Ethiopia. BMC Pregnancy Childbirth. 2012;12(1):6. doi:10.1186/14712393-12-6

2. Ali MM, Park MH, Ngo TD. Levels and determinants of switching following intrauterine device discontinuation in 14 developing countries. Contraception. 2014;90(1):47-53. doi:10.1016/j.contraception. 2014.03.008

3. Ali MM, Sadler RK, Cleland J, Ngo TD, Shah IH. Long-Term Contraceptive Protection Discontinuation and Switching Behaviour. Intrauterine Device (IUD) Use Dynamics in 14 Developing Countries. London: World Health Organization and Marie Stopes International; 2011.

4. Balogun O, Olaomo N, Adeniran A, Fawole A. Implanon sub-dermal implant: an emerging method of contraception in Ilorin, Nigeria. $J$ Med Biomed Sci. 2014;3(1):1-5. doi:10.4314/jmbs.v3i1.1

5. Bhatia P, Nangia S, Aggarwal S, Tewari C. Implanon: subdermal single rod contraceptive implant. J Obstet Gynaecol India. 2011;61 (4):422. doi:10.1007/s13224-011-0066-z

6. Birhane K, Hagos S, Fantahun M. Early discontinuation of implanon and its associated factors among women who ever used implanon in Ofla District, Tigray, Northern Ethiopia. Int J Pharm Sci Rev. 2015;6(3):544 551.

7. Blumenthal P, Voedisch A, Gemzell-Danielsson K. Strategies to prevent unintended pregnancy: increasing use of long-acting reversible contraception. Hum Reprod Update. 2010;17(1):121-137. doi:10.1 093/humupd/dmq026

8. Bradley SE, Schwandt H, Khan S. Levels, trends, and reasons for contraceptive discontinuation. DHS Anal Stud. 2009;20.

9. Burusie A. Reasons for premature removal of implanon among users in Arsi Zone, Oromia Region, Ethiopia. Reprod Syst Sex Disorders. 2015;4 (1).

10. Casey PM, Long ME, Marnach ML, Bury JE. Bleeding related to etonogestrel subdermal implant in a US population. Contraception. 2011;83(5):426-430. doi:10.1016/j.contraception.2010.09.012

11. CSA. Population and housing census of Ethiopia 2017. Available from: https://unstats.un.org/unsd/censuskb20/Attachment489.aspx? AttachmentType=1. Accessed August 7, 2020.

12. Gebremedhin S. Trend and socio-demographic differentials of Caesarean section rate in Addis Ababa, Ethiopia: analysis based on Ethiopia demographic and health surveys data. Reprod Health. 2014;11(1):14. doi:10.1186/1742-4755-11-14

13. Harvey C, Seib C, Lucke J. Continuation rates and reasons for removal among Implanon ${ }^{\circledR}$ users accessing two family planning clinics in Queensland, Australia. Contraception. 2009;80(6):527532. doi:10.1016/j.contraception.2009.05.132

14. Igwe N. Intrauterine contraceptive device use in Abakaliki, southeast Nigeria: a 5-year review. Trop J Med Res. 2016;19(2):138. doi:10.4103/1119-0388.185441

15. Mahumud RA, Hossain MG, Sarker AR, et al. Prevalence and associated factors of contraceptive discontinuation and switching among Bangladeshi married women of reproductive age. Open Access $J$ Contracep. 2015;6:13.

16. Melkamu Asaye M, Syoum Nigussie T, Mequannt Ambaw W. Early Implanon Discontinuation and Associated Factors among Implanon User Women in Debre Tabor Town, Public Health Facilities, Northwest Ethiopia, 2016. Int J Reprod Med. 2018;2018:1-10. doi: $10.1155 / 2018 / 3597487$

17. Muthir J, Nyango D. Indications for removal of etonogestrel implant within two years of use in Jos, Nigeria. East Afr Med J. 2010;87(11).

18. Ott MA, Sucato GS. Contraception for adolescents. Pediatrics. 2014;2014-2300. 
19. Rademacher KH, Vahdat HL, Dorflinger L, Owen DH, Steiner MJ. Global introduction of a low-cost contraceptive implant. In: Kulczycki A, editor. Critical Issues in Reproductive Health. Netherlands: Springer; 2014:285-306.

20. RamaRao S, Lacuesta M, Costello M, Pangolibay B, Jones H. The link between quality of care and contraceptive use. Int Fam Plan Perspect. 2003;29(2):76-83. doi:10.2307/3181061

21. Staveteig S, Mallick L, Winter R. Uptake and Discontinuation of Long-Acting Reversible Contraceptives (LARCS) in Low-Income Countries. ICF International; 2015.

22. Tadesse A, Kondale M, Agedew E, Gebremeskel F, Boti N, Oumer B. Determinant of implanon discontinuation among women who ever used implanon in Diguna Fango District, Wolayita Zone, Southern Ethiopia: a community based case control study. Int J Reprod Med. 2017;2017.
23. Teunissen AM, Grimm B, Roumen FJ. Continuation rates of the subdermal contraceptive Implanon ${ }^{\circledR}$ and associated influencing factors. Eur J Contracept Reprod Health Care. 2014;19(1):15-21. doi:10.3109/13625187.2013.862231

24. WHO. Causes and consequences of contraceptive discontinuation: evidence from 60 demographic and health surveys; 2012. Available from: https://www.who.int/reproductivehealth/publications/family planning/9789241504058/en/. Accessed November 20, 2018.

25. Yalew SA, Zeleke BM, Teferra AS. Demand for long acting contraceptive methods and associated factors among family planning service users, Northwest Ethiopia: a health facility based cross sectional study. BMC Res Notes. 2015;8(1):29. doi:10.1186/s13104-015-0974-6

\section{Publish your work in this journal}

Open Access Journal of Contraception is an international, peerreviewed, open access, online journal, publishing original research, reports, reviews and commentaries on all areas of contraception. In addition to clinical research, demographics and health-related aspects, the journal welcomes new findings in animal and preclinical studies relating to understanding the biological mechanisms and practical development of new contraceptive agents. The manuscript management system is completely online and includes a very quick and fair peer-review system. Visit http://www.dovepress.com/testimonials. php to read real quotes from published authors. 